\title{
Women's Attitudes and Beliefs Regarding Cervical Cancer Prevention at Rural Health Care Facilities in Limpopo Province of South Africa
}

\author{
AG Mudau*, AK Tugli and J Mabunda \\ Department of Public Health, University of Venda, South Africa
}

Submission: October 02, 2017; Published: November 27, 2017

*Corresponding author: AG Mudau, Department of Public Health, University of Venda, Private Bag X5050,Thohoyandou, 0950, South Africa, Email: mudauazwinndini@gmail.com

\begin{abstract}
The study assessed the attitudes and beliefs of women attending health care facilities regarding cervical cancer screening. This crosssectional study involved 500 participants chosen conveniently from a total of 9868 outpatient women aged $\geq 18$ years from Tshilidzini Hospital and Tshilidzi Gateway clinic. Self- administered questionnaires were used to collect data which were analysed using descriptive statistics and Pearson's correlation method. Whilst about 1 in every 3 participants ( $=203 ; 59.0 \%)$ disagreed that papnicolaou (pap) is painful, nearly 7 in every 10 participants disagreed that Pap smear is embarrassing and at the same time agreed that there is no need to worry about signs and symptoms of cervical cancer. Furthermore, this study established a positive significant correlation between the belief that cervical cancer can be diagnosed by pap smear and ever heard about pap smear $(r=0.405 ; \mathrm{p}<0.01)$. Health education and promotion is, paramount in the Department of Health education and promotion is, therefore, paramount in the Department of Health' initiative of raising cervical cancer awareness among South African women.
\end{abstract}

Keywords: Attitudes; Beliefs; Pap smear; Screening; Cervical cancer

\section{Opinion}

Cervical cancer is a preventable non- communicable disease of public health importance and is the second most common cancer in women word-wide, with $80 \%$ of cases occurring in developing countries including South Africa [1]. Women's negative attitudes and beliefs towards this condition poses a huge challenge in its prevention and cure. A study conducted in Nigeria in 2007 revealed cancer that women seek medical solution to cervical cancer during the late stage of the disease [2]. The study further showed that women had been reluctant to undergo cervical screening because of the embarrassment felt when exposing their genital organs for examination and even the fear of having positive screening results. This source further revealed that $31.4 \%$ of women had never had a cervical cancer screening done in the past; 7,3\% did not even see themselves at risk of contracting the disease despite their being sexually active and some of women did not perceive cervical cancer as serious disease. In recent study in Libreville-Gabon, Assoumo et al. [3] stated that of all the study participants, only $126(27.9 \%)$ of them had heard of pap smear test out of $414(91.6 \%)$ who reported hearing about cervical cancer.
According to Lyimo \& Beran [4], women in Somalia developed a negative outlook on screening due to the embarrassment associated with female genital mutilation coupled with cultural barriers that undermine and relegate the role and dignity of women. Chankapa et al. [5] point out cultural beliefs that ignore preventative medicine create isolation from the community at large and enforced language barriers may interfere with women's access and utilization of available health care. In addition, sexuality is a very sensitive and secretive topic in many Eastern cultures and it is unlikely to be discussed in homes or within small community settings [5]. It is also interesting to note that despite a growing number of screening programme, but would often not return or do follow up appointments that would have been recommended by their health practitioners [6].

The study conducted in the USA by Uysal \& Brisel [7] indicated that despite the overall downward trend in cervical cancer, there exists a disparity in mortality rates for cervical cancer related deaths among certain ages as well as geographic and socio-economic groups. It was noted that lower education, 
lack of health coverage and rural location are associated with inadequate preventative cervical cancer screening. Similar findings in Turkey, indicated that an increase in the level of education and age as well as the presence of social security, resulted in the frequency of pap smear testing [7]. Among many South Asian women, there is strong belief that cervical cancer is stigmatising, painful and untreatable thus hardening their attitude towards participation in cervical cancer screening [8].

In South Africa, cervical cancer is rife among black women [1], and approximately 3,680 women die of cervical cancer every year and one in every 41 women will within their lifetime develop cervical cancer $[9,10]$. In their study, Uyssal \& Birsel [7] established that women having a pap smear were associated with $70 \%$ lower odds of developing cervical cancer compared to those who have never been screened, but among black women Adentola (2011) found that $60.5 \%$ never received pap smear .A variety of factors ranging from low socio-economic status, low level of education, unemployment to superstitious beliefs about the disease can be adduced to make it difficult for women in South Africa to accept health care or seek early detection of cervical cancer. As the population of women continues to increase in the midst of wide spread superstition in South Africa, especially in the Limpopo Province, the researchers deemed it necessary to assess the attitudes and beliefs of women attending rural health facilities regarding cervical cancer screening.

\section{Methodology}

\section{Study design}

A cross sectional design was employed for this study. This design enabled the researchers to collect data about the attitudes and beliefs of women attending rural health facilities regarding cervical cancer screening at one point in time [11]. Thus the attitudes, regarding cervical cancer screening were appropriately assessed and the relationships among variables determined.

\section{The study setting}

The study was conducted in Tshilidzini hospital and Tshilidzi Gateway clinic which offer in-patients and out-patient services to a population of approximately 1.5 million people in the Thulamela B Municipality. This is the main that hospital serves as referral facility to 28 public health facilities and the hospital was chosen because it runs both outpatient and inpatient services, with a daily average of approximately 310 outpatient visits. It has 53 doctors, 5 specialists, 6 dentists, 284 professional nurses, 168 enrolled nurses and 171 auxiliary nurses. The second setting (Tshilidzi Gateway clinic) was opened in December 2006 and is situated in an informal settlement area. It operates within the hospital (Tshilidzini) and attends to non-emergency services. This clinic caters for all types of primary health care services, such as family planning, chronic illness management, antenatal care, well-baby services, and minor ailments. HIV \& AIDS and mental health care services. Tshilidzi Gateway clinic provides
10 hour services a day and 7 days a week. It opens at $07 \mathrm{~h} 00$ and closes at $18 \mathrm{~h} 00$.An average of 200 patients are seen daily at the clinic.

\section{Population and sample size}

The study targeted 9868 women served by Tshilidzini hospital outpatient department and Gateway clinic. Of this number sample size of $\mathrm{n}=500$ was estimated, and a convenient sampling approach was used to select the participants. Women aged 18 years and older volunteered to participate in the study.

\section{Instrument and data collection procedure}

A structured questionnaire was used as the instrument to collect data. The questionnaire contained close-ended questions to measure the attitudes of women aged 18 years and older at Tshilidzini hospital. The questionnaires was developed in English and translated into local Tshivenda language for women who preferred the native language version. The Tshivenda translation was done by language expert. It was back translated into English by a language expert to ensure that it retains its original content. Attitudes and beliefs about cervical cancer were assessed using the following closed response options: $S A=$ strongly Agree, $A=$ Agree, $\mathrm{D}=$ Disagree, $\mathrm{SD}=$ Strongly Disagree. The questionnaires was designed to obtain the relevant information from the participants on a scheduled date and time decided by the hospital authority to ensure that health activities were not disrupted.

The instrument was refined after pre-testing it on 50 women at Tshilidzini hospital its reliability. The participants who were involved in the pre-testing of the instrument were not included in the main study. The study was conducted in June, 2013. Access and convenient venues at the study sites were negotiated with institutional authorities. All women above the age of 18 years, attending Tshilidzini hospital that consented to participate in the study were assisted to complete the questionnaire

\section{Data analysis}

After scrutinizing all the questionnaires, the data were captured and analysed using the statistical package for social sciences (SPSS) version 22. Analysis involved the simple descriptive statistics and correlations. Correlation was set to be significant at the 0.01 and 0.05 levels (2-tailed). Frequency tables were the main methods of data presentation.

\section{Ethical consideration}

The University of Venda Ethics Committee issued the ethical clearance certificate (project no. SHS/14/ph/06/1605) for the study to be conducted. Furthermore, permission to conduct the study was obtained from the Limpopo Department of Health as well as the management of Tshilidzini hospital and Tshilidzi Gateway clinic. Informed consent was obtained from the participants after the study and its objectives were explained to them. Participants' confidentiality, privacy and voluntary participation were respected. 
Results

\section{Participant' attitudes and beliefs}

Table 1: Attitudes and beliefs of women regarding cervical cancer.

\begin{tabular}{|c|c|c|c|c|}
\hline Items on Attitudes and Beliefs (n=s500) & SA n(\%) & An n(\%) & D n(\%) & SD n(\%) \\
\hline I worry about getting cervical cancer & $33(7.7 \%)$ & $186(43.6 \%)$ & $191(44.7)$ & $17(4.0 \%)$ \\
\hline I am afraid of Pap smear & $12(2.6 \%)$ & $150(32.8 \%)$ & $246(53.8 \%)$ & $49(10,7 \%)$ \\
\hline I am not at risk of developing cervical cancer & $21(5.2 \%)$ & $228(56.2 \%)$ & $147(36.2 \%)$ & $10(2.5 \%)$ \\
\hline It is not necessary to do pap smear & $22(4.7 \%)$ & $44(9.4 \%)$ & $253(53.8 \%)$ & $151(32.1 \%)$ \\
\hline Pap smear is painful & $4(1.2 \%)$ & $107(31.1 \%)$ & $203(59.0 \%)$ & $30(8.7 \%)$ \\
\hline Pap smear is embarrassing & $3(0.7 \%)$ & $63(15.4 \%)$ & $282(69.1 \%)$ & $60(14.7 \%)$ \\
\hline I prefer a female health care worker & $57(12.2 \%)$ & $57(12.2 \%)$ & $246(52.3 \%)$ & $108(23.1 \%)$ \\
\hline No need to worry about signs and symptoms of cervical cancer & $21(4.2 \%)$ & $228(45.6 \%)$ & $241(48.2 \%)$ & $10(2.0 \%)$ \\
\hline All women are at risk of developing cervical cancer & $20(4.0 \%)$ & $357(71.4 \%)$ & $110(22 \%)$ & $13 \mathrm{C} 2.6 \%)$ \\
\hline
\end{tabular}

As shown in Table 1, Participants' responses to items on attitudes and beliefs pertaining to cervical cancer were summarised using 4 (four) response options: "Strongly Agree (SA)", "Agree ( A)", "Disagree (D)", and "Strongly Disagree ( SD)". As regards the attitude of being worried about cervical cancer almost equal proportion of participants agreed $(n=186$;
43.6\%) and disagreed $(\mathrm{n}=191 ; 44.7 \%)$. Whilst about 1 in every 3 participants $(n=203 ; 59.0 \%)$ disagreed that taking pap smear is painful, nearly 7 in every 10 participants disagreed that pap smear is embarrassing at the same time they agreed that it is not necessary to worry about signs and symptoms of cervical cancer (Table 1).

Table 2: Correlation of age, marital status and education with preventability of cervical cancer.

\begin{tabular}{|c|c|}
\hline Variable & Ever Heard about Pap Smear \\
\hline Having had a Pap smear done & 0.329 \\
\hline Belief that cervical cancer can be diagnosed by Pap smear & 0.405 \\
\hline Age of participants & 0.268 \\
\hline Marital status of participants & 0.186 \\
\hline Variable & Having Ever had a Pap Smear Done \\
\hline Belief that cervical cancer can be diagnosed by Pap smear & 0.130 \\
\hline Variable & Belief that Cervical Cancer can be Diagnosed By Pap Smear? \\
\hline Age of participants & 0.130 \\
\hline Marital status of participants & 0.215 \\
\hline \multicolumn{2}{|c|}{ Correlation is significant at the 0.01 level (2-tailed). } \\
\hline \multicolumn{2}{|c|}{ Correlation is significant at the 0.05 level (2- tailed). } \\
\hline
\end{tabular}

\section{Relationships between some variables of the study}

In this study, Pearson's rho ${ }^{\circledR}$ correlation coefficient was used as the descriptive statistic for expressing the magnitude (strength of the relationship) and direction of the association between knowledge and other related variables, with $\mathrm{p}<0.01$ and $\mathrm{p}<0.05$ taken as the statistically significant levels. The correlations were calculated using the SPSS statistical package (version 22). Table 2 presents the correlation between some study variables. Varying degrees of statistical significance $(\mathrm{p}<0.01)$ for all pairs of variables were found (Table 2). More specifically, the belief that cervical cancer can be diagnosed by Pap smear shows positive significant correlation with ever heard about Pap smear $(\mathrm{r}=0.405 ; \mathrm{p}<0.01)$ and also having ever had a Pap smear done $(r=0.487 ; \mathrm{p}<0.01)$.

\section{Discussion}

This study assessed the attitudes and beliefs of women attending a rural hospital regarding cervical cancer screening. Attitudes and beliefs play an important part in health seeking behaviours of people and also the way people view the world around them. Consistent with these findings, Lyimo \& Beran [4] reported that women in Somalia developed a negative outlook on cervical cancer screening due to the embarrassment associated with female genital mutilation coupled with cultural barriers that undermine and relegate the role and dignity of women.

Superstitious beliefs, ignorance and negative attitudes are a threat to overcoming the hazards posed by cervical cancer. This notion among the participants does have a strong bearing 
on participants' level of education but can compound and exacerbate the situation of cervical cancer especially in poor communities in developing countries in Africa and Asia. It is not surprising when Bradley, Risi \& Denny [12] pointed out South African women who are less likely to know about and obtain Pap smear tend to be poorer, less educated and unemployed. Parallel to this assertion, [8] also states that among many South Asian women, there is a strong belief that cervical cancer is stigmatising, painful and untreatable thus hardening their attitude towards their participation in cervical cancer screening.

According to Mosavel et al. [1], cervical cancer is a preventable non- communicable disease of public health importance and is the second most common cancer in women world-wide, with $80 \%$ of cases occurring in developing country including South Africa, but negative attitude of women towards this condition poses a huge challenge in its preventive and cure. Chankapa et al. [5] argue that cultural beliefs that ignore modern preventative medicine may interfere with women's access and utilisation for health care. This may also contribute to lack of health seeking behaviours as pointed out by Adentolaw (2011) in his study conducted in Nigeria in 2007 which revealed that women seek medical solution to cervical cancer during the late stage of the disease.

Though the South African National Department of Health [13] introduced a screening policy that provides Free Pap smear every 10years to women who are 30 years and older, response to this initiative is still poor. In this study, superstitious beliefs, ignorance and other reasons may be partly blamed for about a third of the participants stating that they either stronglyagreed or agreed that they were afraid of taking Pap. This finding resonates with those of Mosavel et al. [1] who reported in their study that fewer black South Africans knew what a pap smear was or the importance of Pap smear. In a recent study [3] among Gabonese women, reasons adduced for not undergoing Pap smear screening were neglect, lack of financial resources, fear of discovering a serious disease and deeming it unimportant. Furthermore, since in this study established a positive significant correlation between the belief that cervical cancer can be diagnosed by Pap smear and ever heard about Pap smear, it therefore implies that health education and promotion will be key in the Department of Health's drive and initiatives of raising cervical cancer awareness campaign among South African women [14].

\section{Limitation of the Study}

The study was conducted in Tshilidzini Hospital and Gateway clinic in Vhembe District of Limpopo Province; and as such, the results do not represent all women who attend health facilities beyond the confines of the hospital and clinic question.

\section{Conclusion}

This study demonstrate that negative attitudes and unrealistic beliefs about cervical cancer screening are still rife among the participants. This picture signals a bleak and doom future for the management and eradication of cervical cancer among Black South African women. A lot health education and promotion is needed at the primary health care level targeting especially the rural and semi-urban communities.

\section{Recommendations}

Cervical cancer is a preventable disease and as such the following recommendations are made:

A. The Department of Health must develop programmes aimed at early detection of precancerous conditions through the Papanicolaou cytology screening (Pap smear) at all primary health care facilities.

B. Social media must be effectively employed to disseminate and encourage health seeking behaviours, pertaining to cervical cancer issues among adult women.

\section{References}

1. Mosavel M, Simon C, Oakar C, Meyer S (2009) Cervical cancer attitudes and beliefs- a Cape Town community responds on World Cancer day. J Cancer Educ 24(2): 114-119.

2. Adetola TD (2011) Knowledge, attitudes and practice of cervical cancer screening among women in primary health care centre in Ibadan South East local government area Oyo state. West African Journal of Nursing 22(1): 2-12.

3. Assoumou SZ, Mabika BM, Mbiguino AN, Mouallif M, Khattabi A, et al. (2015) Awareness and knowledge regarding cervical cancer, pap smear screening and human papilolomavirus infection in Gabonese women. BMC Womens Health 15: 37.

4. Lyimo FS, Beran TN (2012) Demographic, knowledge, attitudinal and accessibility factors associated with uptake of cervical cancer screening among women. In a rural district of Tanzania. Three public policy implications BMC Public Health 12(22): 1-8.

5. Chankapa YD, Pal R, Tserig D (2011) Correlate of cervical cancer screening among underserved women. Indian Journal of Cancer 48(1): $1-10$.

6. Duffet ledger LA, Letoumeau Nl, Cross JC (2008) Cervical cancer screening practices among University women. J Obstet Gynecol Neonatal Nurs 37(5): 572-581.

7. Uysal A, Birsel A (2009) Knowledge about cervical cancer risk factors and pap testing behaviour among Turkish women. Asian Pac J Cancer Prev 10(3): 345-350.

8. World Health Organisation (2010) Human papilloma virus and related cancers in South Africa. WHO, Switzerland, Geneva, ( $3^{\text {rd }}$ edn).

9. (2001) National Cancer Registry.

10. Megevand E, Denny L, Dehacck K, Socter R, Bloch B (2003) Acetic Acid visualization of the cervix. An alternative to cytological screening in Visual inspection of the uterim cervix with acetic acid (VIA). A critical review and selected articles PAHO publication 1: 58-61.

11. Brink H, Christa VW, Gisela VR (2008) Fundamentals of research methodology for health care professionals, $\left(2^{\text {nd }} e d n\right)$, Juta and Company Ltd, Cape Town, South Africa, pp. 1-226.

12. Bradeley J, Risi L, Denny L (2004) Widening the cervical cancer screening net. In a South African township: Who are the underserved? Health Care Women Int 25(3): 227-241. 
13. (2000) National Department of Health. National guideline on cervical cancer screening programme. Department of Health, Pretoria, South Africa, pp. 1-12.
14. Deny L (2006) Prevention of cervical cancer. In Health System Trust. South African Health Review 2006(1): 333-346.

\section{Your next submission with Juniper Publishers} will reach you the below assets

- Quality Editorial service

- Swift Peer Review

- Reprints availability

- E-prints Service

- Manuscript Podcast for convenient understanding

- Global attainment for your research

- Manuscript accessibility in different formats ( Pdf, E-pub, Full Text, Audio)

- Unceasing customer service

Track the below URL for one-step submission https://juniperpublishers.com/online-submission.php 